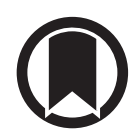

CrossMark

\title{
The overlap between bronchiectasis and chronic airway diseases: state of the art and future directions
}

\author{
Eva Polverino ${ }^{1,2,3}$, Katerina Dimakou ${ }^{4}$, John Hurst ${ }^{5}$, \\ Miguel-Angel Martinez-Garcia ${ }^{6}$, Marc Miravitlles (10) ${ }^{1,2,3}$, Pierluigi Paggiaro ${ }^{7}$, \\ Michal Shteinberg ${ }^{8,9}$, Stefano Aliberti (10 ${ }^{10,11}$ and James D. Chalmers ${ }^{12}$
}

Affiliations: ${ }^{1}$ Pneumology Dept, Hospital Universitari Vall d'Hebron (HUVH), Barcelona, Spain. ${ }^{2}$ Institut de Recerca Vall d'Hebron (VHIR), Barcelona, Spain. ${ }^{3}$ CIBER, Spain. ${ }^{45}$ th Pulmonology Dept, "Sotiria" Chest Hospital, Athens, Greece. ${ }^{5} \mathrm{UCL}$ Respiratory, University College London, London, UK. ${ }^{6}$ Pneumology Dept, Polytechnic and University La Fe Hospital, Valencia, Spain. ${ }^{7}$ Dept of Surgery, Medicine, Molecular Biology and Critical Care, University of Pisa, Pisa, Italy. ${ }^{8}$ Pulmonology Institute and Cystic Fibrosis Center, Carmel Medical Center, Haifa, Israel. 'Technion-Israel Institute of Technology, The B. Rappaport Faculty of Medicine, Haifa, Israel. ${ }^{10}$ Dept of Pathophysiology and Transplantation, University of Milan Internal Medicine Dept, Respiratory Unit and Cystic Fibrosis Adult Center, Milan, Italy. ${ }^{11}$ Fondazione IRCCS Ca' Granda Ospedale Maggiore Policlinico, Milan, Italy. ${ }^{12}$ Scottish Centre for Respiratory Research, University of Dundee, Ninewells Hospital and Medical School, Dundee, UK.

Correspondence: Eva Polverino, Pneumology Dept, Hospital Universitari Vall d'Hebron (HUVH), Passeig Vall d'Hebron, 119-129, 08035 Barcelona, Spain.

E-mail: eva.polverinolavhir.org

@ERSpublications

Bronchiectasis is a heterogeneous disease and frequently overlaps with other chronic airway diseases. Management of these overlap conditions is particularly challenging in terms of diagnosis and therapy, and requires future research. http://ow.ly/snLK30lsrkr

Cite this article as: Polverino E, Dimakou K, Hurst J, et al. The overlap between bronchiectasis and chronic airway diseases: state of the art and future directions. Eur Respir J 2018; 52: 1800328 [https://doi. org/10.1183/13993003.00328-2018].

ABSTRACT Bronchiectasis is a clinical and radiological diagnosis associated with cough, sputum production and recurrent respiratory infections. The clinical presentation inevitably overlaps with other respiratory disorders such as asthma and chronic obstructive pulmonary disease (COPD). In addition, $4-72 \%$ of patients with severe COPD are found to have radiological bronchiectasis on computed tomography, with similar frequencies (20-30\%) now being reported in cohorts with severe or uncontrolled asthma. Co-diagnosis of bronchiectasis with another airway disease is associated with increased lung inflammation, frequent exacerbations, worse lung function and higher mortality. In addition, many patients with all three disorders have chronic rhinosinusitis and upper airway disease, resulting in a complex "mixed airway" phenotype.

The management of asthma, bronchiectasis, COPD and upper airway diseases has traditionally been outlined in separate guidelines for each individual disorder. Recognition that the majority of patients have one or more overlapping pathologies requires that we re-evaluate how we treat airway disease. The concept of treatable traits promotes a holistic, pathophysiology-based approach to treatment rather than a syndromic approach and may be more appropriate for patients with overlapping features.

Here, we review the current clinical definition, diagnosis, management and future directions for the overlap between bronchiectasis and other airway diseases. 


\section{Introduction}

Owing to increasing knowledge and awareness, bronchiectasis is not considered a rare condition but a relevant chronic lung disease characterised by permanent bronchial damage and a broad spectrum of chronic respiratory and systemic symptoms [1]. From a radiological perspective, the most accepted diagnostic criteria were defined by NAIDICH et al. [2] using a number of direct signs (broncho-arterial ratio $>1$, lack of bronchial tapering, visualisation of peripheral bronchi within $1 \mathrm{~cm}$ of the costal pleura in contact with the mediastinal pleura) and indirect signs (peribronchial thickening, mucus plugging, mosaic pattern, centrilobular nodules, tree-in-bud nodules, focal areas of air trapping, atelectasis/consolidation) $[2,3]$. One of the major characteristics of the bronchiectasis population is its heterogeneity. Patients present with bronchiectasis at variable ages (from early life to older age), have a varied symptom burden (from intermittent dry cough to daily bronchorrhea and frequent exacerbations) and have different prognoses depending on numerous factors such as underlying causes, presence of chronic Pseudomonas aeruginosa infection and comorbidities $[1,4-6]$.

It is well known that the underlying causes of bronchiectasis can be responsible for relevant differences in terms of clinical presentation, evolution and prognosis. This is particularly evident in some pathological conditions such as associated respiratory diseases (e.g. chronic obstructive pulmonary disease (COPD), asthma, allergic bronchopulmonary aspergillosis (ABPA), sinusitis) or systemic inflammatory diseases (e.g. rheumatoid arthritis) [7-12]. Some recent studies suggest that bronchiectasis and COPD coexist in $20-60 \%$ of cases [8], and coexisting disease can result in increased symptom burden, a reduced therapeutic arsenal and a worse prognosis compared to COPD or bronchiectasis alone $[8,9,13,14]$. Unfortunately, it is not clear whether the relationship between these two respiratory conditions is a causal connection or a chance association. Nevertheless, the coexistence of bronchiectasis and COPD deserves special attention in terms of therapy and the prevention of disease progression.

In recent years, the association between asthma and bronchiectasis has shown potentially specific features in terms of age, clinical presentation, risk of exacerbations and diagnostic and therapeutic options $[4,7,15]$. Unfortunately, there is still limited information on the prognosis of asthma-bronchiectasis overlap, although it has been suggested that patients with severe asthma with bronchiectasis may have a worse prognosis (more symptoms and exacerbations) than asthma patients without bronchiectasis [16-18].

More recently, it has been shown that ABPA and asthma play a considerable role in bronchiectasis $[4,19]$. Once again, the nature of this association is not completely understood but the clinical presentation and treatment of ABPA are characteristic and specific, unlike other bronchiectasis subgroups. This suggests that ABPA is a specific clinical entity rather than an overlap between two different conditions.

Up to $75 \%$ of bronchiectasis patients may have upper airway disease and present with severe daily symptoms of nasal congestion, facial pain and/or loss of smell [20]. Primary ciliary dyskinesia (PCD) is a frequent cause of chronic rhinosinusitis (CRS) and bronchiectasis, but rhinosinusitis is relatively frequent in bronchiectasis even in the absence of primary ciliary dysfunction [21]. Common predisposing factors or the obvious anatomical connection between upper and lower airways could explain this strong association. Such upper airway symptoms are also common in asthma and COPD.

An important factor in the mechanism of airway disease is the nature of the bronchial inflammatory process. In bronchiectasis, inflammation is predominated by neutrophils, with elevated levels of interleukin-8 (IL-8) $[6,22-25]$. In a study exploring inflammatory cells in the sputum of patients with bronchiectasis, neutrophils predominated over eosinophils, with large variance between patients: the median neutrophil percentage was 79\% (range 1.5-98\%) and eosinophil percentage was $0.8 \%$ (range 0-70\%) [23]. In this cohort, 26\% of patients had upper airway involvement and $16 \%$ had airway reversibility. Elevated neutrophil levels in sputum were associated with more exacerbations, low lung function, and greater duration and severity of bronchiectasis. Similarly, neutrophil elastase, derived from neutrophils, was found to be associated with an increased severity of bronchiectasis [25]. Levels of inflammatory mediators in the sputum of bronchiectasis were also found to be heterogeneous, with increased levels of IL-8, IL-13, tumour necrosis factor- $\alpha$ (TNF- $\alpha$ ) and IL-17, as well as elevated levels of the type 2 mediator IL- 4 in a minority of patients. Increased IL-17 predominated in bronchiectasis secondary to primary immune deficiency, but otherwise no differences were found in groups of patients with different bronchiectasis aetiologies [6]. Inflammation is heterogeneous in patients with asthma and CRS, but the majority have an eosinophilic, type $2 \mathrm{~T}$ helper cell-mediated inflammation [26]. Similarly, in COPD there is evidence for neutrophil-mediated inflammation, but it has recently been suggested that sputum eosinophilia is associated with more exacerbations. In view of the heterogeneity of airway inflammation in bronchiectasis, it is possible that different inflammatory profiles explain the differences in clinical phenotypes and overlapping airway diseases.

In addition to these chronic inflammatory diseases, gastro-oesophageal reflux disease (GERD) is also associated with bronchiectasis, particularly in the presence of nontuberculous mycobacterial (NTM) 
infection, although a causal relationship has not been demonstrated [27, 28]. The hypothesis is that recurrent gastro-oesophageal reflux could irritate upper airways, causing bronchial hyperresponsiveness and lung infections such as aspiration pneumonia or NTM infection, consequently leading to bronchiectasis. It does seems that GERD could worsen the symptoms of bronchiectasis and a Korean group suggested that treatment with proton-pump inhibitors in bronchiectasis patients with a high body mass index could improve lung function [29]. However, the same association between GERD and worse respiratory symptoms can be found for asthma, CRS and COPD [30, 31]. Although the association between GERD and all these chronic airway diseases is clear, a causal connection has not yet been established and further investigation considering potential confounding factors is surely needed.

In addition, it is worth remembering that cystic fibrosis (CF) is also a cause of bronchiectasis but, owing to peculiarities in terms of its pathophysiology (a genetic defect of the CF transmembrane conductance regulator (CFTR)) and clinical management (systemic disease, CFTR modulator therapies), it is not covered in this review [32-34].

Another inheritable but polygenic condition that causes bronchiectasis is PCD. This is a rare condition whose genetics and pathophysiology are still not fully known. Typically, PCD patients show sinus and ear involvement, aside from bronchiectasis, and a variable combination of fertility disorders and, in rare cases, situs inversus [21,35].

In the face of the heterogeneity of bronchiectasis, it is crucial that the pathophysiological determinants, clinical outcomes and prognostic factors of specific subgroups or phenotypes are investigated to improve the management of this disease. An emerging concept in respiratory medicine is the recognition of overlap syndromes which have specific diagnostic, prognostic and therapeutic implications, with asthma-COPD overlap and interstitial pulmonary fibrosis with emphysema being examples of well-characterised multipathology syndromes [36-40].

This manuscript will focus on the most common associations between bronchiectasis and other chronic respiratory diseases in order to review current evidence and outline major research needs.

\section{Overlap COPD and bronchiectasis \\ Prevalence of bronchiectasis in COPD patients}

There is a lack of large epidemiological studies in patients with COPD employing high-resolution computed tomography (HRCT) to assess the prevalence of bronchiectasis; therefore, there are only a few prevalence estimates for this association (table 1). However, despite the possibility of the chance coexistence of bronchiectasis and COPD in the same patient and the frequent misdiagnosis of the two conditions [41], the majority of case series in patients with severe COPD have identified a high frequency of bronchiectasis, albeit ranging from $4 \%$ to $72 \%[8,42]$. There may be several reasons for this wide range of prevalence: the presence of vascular hypertension frequently results in misdiagnosis and computed tomography (CT) without high-resolution algorithms is the main cause of under-diagnosis of bronchiectasis. In contrast, erroneous diagnosis (over-diagnosis) of bronchiectasis in COPD may be caused by, for example, the presence of bronchial dilatations in healthy elderly individuals, interstitial lung disease or emphysema usually without bronchial wall thickening (table 2). Limitations in study design also account for the misdiagnosis of bronchiectasis in COPD. The retrospective design of some studies, the inclusion of non-consecutive patients and the use of non-validated scores are among the most frequent causes of under- or over-diagnosis of bronchiectasis in COPD (table 3).

It is important to recognise that the classical criteria for the radiological diagnosis of bronchiectasis (especially a broncho-arterial ratio $>1$, usually with airway wall thickening) [3] may not apply to patients with other cardiopulmonary diseases or to elderly patients. In cases of airway disease, a decrease in the vessel diameter due to hypoxic vasoconstriction or an increase in this diameter in the presence of vascular hypertension may lead to under- or over-diagnosis of radiological bronchial dilatation or bronchiectasis (figure 1a) [43, 44]. Indeed, almost $20 \%$ of healthy elderly subjects have a broncho-arterial ratio $>1$ in some pulmonary segments without any symptoms of bronchiectasis, usually without increased bronchial wall thickening [45].

\section{Association of bronchiectasis and COPD}

COPD is a physiological diagnosis made in the presence of an appropriate exposure history (mainly tobacco smoking) that in some patients is associated with airway wall changes [46, 47]. Bronchiectasis is a radiological diagnosis that in some cases is associated with poorly reversible airflow obstruction [48-50]. If there is no significant exposure history, and outside the context of a known deficiency such as $\alpha_{1}$-antitrypsin deficiency, there cannot be an overlap between bronchiectasis and COPD, because such a case does not fulfil the diagnostic criteria of COPD. In this situation, airflow obstruction is best considered one component of bronchiectasis severity. Airflow obstruction is recognised as a severity marker in 
TABLE 1 Characteristics of the studies analysing the prevalence and outcomes related to the presence of bronchiectasis in COPD patients

$\begin{array}{llllll}\text { Study } & \text { Selection } & \text { n } & \text { Age years }^{\#} & \text { Male sex } \% & \text { Main objective }\end{array}$
criteria

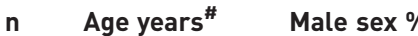

Main objective

$\mathrm{BCH}$ criteria

$\mathrm{BCH}$ prevalence \%

\begin{tabular}{|c|c|c|c|c|c|c|c|}
\hline $\begin{array}{l}\text { O'BRIEN et al., } 2000 \\
\text { [41] }\end{array}$ & $\begin{array}{l}\text { Primary care diagnosis of COPD with } \\
\text { acute exacerbation }\end{array}$ & 110 & 66.5 & 58 & Diagnosis of COPD in primary care & Naidich and Hansell & $\begin{array}{c}29 \\
\text { Cystic: } 15.5 \\
\text { Varicose: } 12.5 \\
\text { Tubular: } 72\end{array}$ \\
\hline $\begin{array}{l}\text { Patel et al., } 2004 \\
\text { [51] }\end{array}$ & Stable moderate-to-severe COPD & 54 & 69 & - & $\begin{array}{l}\text { Prevalence and extent of } \mathrm{BCH} \text { and } \\
\text { emphysema }\end{array}$ & $\begin{array}{l}\text { Naidich (diagnosis) and } \\
\text { Smith (0-4 points } \\
\text { grading) } \\
\text { Score }<2 \text { was considered } \\
\text { normal }\end{array}$ & $\begin{array}{c}50 \\
\text { Lower lobes: } 66.7\end{array}$ \\
\hline $\begin{array}{l}\text { RocHe et al., } 2007 \\
\text { [52] }\end{array}$ & Hospitalised COPD & 118 & $68.4 \pm 12.1$ & 74 & Sputum examination analysis & $\begin{array}{l}\text { Bronchi/vessel (diameter) } \\
\quad>1\end{array}$ & 19.8 \\
\hline $\begin{array}{l}\text { GARCIA-VIDAL et al., } \\
2009 \text { [53] }\end{array}$ & $\begin{array}{l}\text { Hospitalised COPD } \\
\text { (previous BCH were excluded) }\end{array}$ & 88 & $72.1 \pm 10$ & 95 & Incidence and risk factors for PA & $\begin{array}{l}<2 \text { affected segments were } \\
\text { considered normal }\end{array}$ & 52 \\
\hline $\begin{array}{l}\text { Agusti et al., } 2010 \\
\text { [54] }\end{array}$ & $\begin{array}{l}\text { ECLIPSE cohort } \\
\text { of GOLD II-IV stable COPD } \\
\text { (previous BCH were excluded) }\end{array}$ & 2164 & $63.4 \pm 7.1$ & 65 & $\begin{array}{l}\text { Characterisation of COPD } \\
\text { heterogeneity }\end{array}$ & No criteria available & $\begin{array}{c}4 \\
\text { Stage II: } 1-2 \\
\text { Stage III: 3-6 } \\
\text { Stage IV: } 7-9\end{array}$ \\
\hline $\begin{array}{l}\text { BAFADHEL et al., } 2011 \\
\text { [55] }\end{array}$ & $\begin{array}{l}\text { Stable COPD lonly if previous CT } \\
\text { scan) }\end{array}$ & 75 & $67(43-88)^{\pi}$ & 58 & CT scan COPD phenotypes & $\begin{array}{l}\text { Naidich (diagnosis) and } 0- \\
\quad 4 \text { points (grading) }\end{array}$ & 27 \\
\hline $\begin{array}{l}\text { Martínez-García } \\
\text { et al., } 2011 \text { [56] }\end{array}$ & $\begin{array}{l}\text { Stable moderate-to-severe COPD } \\
\text { (previous } \mathrm{BCH} \text { were excluded) }\end{array}$ & 92 & $71.3 \pm 9.3$ & 99 & Factors associated with $\mathrm{BCH}$ & $\begin{array}{l}\text { Naidich } \\
\quad>1 \text { segment }\end{array}$ & $\begin{array}{c}57.6 \\
\text { Moderate: } 34.7 \\
\text { Severe: } 72.5 \\
\text { Cylindrical: } 90.6 \\
\text { Lower lobes: } 60.4\end{array}$ \\
\hline $\begin{array}{l}\text { ARRAM et al., } 2012 \\
\text { [57] }\end{array}$ & Moderate-to-severe stable COPD & 69 & $59.4-60.4^{+}$ & 95 & Incidence of $\mathrm{BCH}$ & No criteria available & $\begin{array}{c}47.8 \\
\text { Moderate: } 31.3 \\
\text { Severe: } 62.2 \\
\text { Cylindrical: } 82 \\
\text { Lower lobes: } 67 \\
\text { Bilateral: } 73\end{array}$ \\
\hline $\begin{array}{l}\text { Steward and MASELLI, } \\
2012 \text { [58] }\end{array}$ & Stable COPD GOLD II-IV COPDGene & 3752 & $62.8-65.5^{\S}$ & 55 & $\begin{array}{l}\text { Prevalence and clinical impact of } \\
\mathrm{BCH}\end{array}$ & Visual assessment & $\begin{array}{l}20.8 \\
\text { GOLD II: } 18.8 \\
\text { GOLD III: } 24 \\
\text { GOLD IV: } 24\end{array}$ \\
\hline $\begin{array}{l}\text { MARTinez-GaRcia } \\
\text { et al., } 2013 \text { [59] }\end{array}$ & $\begin{array}{l}\text { Stable moderate-to-severe COPD } \\
\text { (previous } \mathrm{BCH} \text { were excluded) }\end{array}$ & 201 & $70.3 \pm 8.9$ & 90.5 & Prognostic value of $\mathrm{BCH}$ & $\begin{array}{l}\text { Naidich } \\
\quad>1 \text { segment } \\
\text { Bhalla (grading) }\end{array}$ & $\begin{array}{c}\quad 57.2 \\
\text { Cylindrical: } 87 \\
\text { Lower lobes: } 81 \\
\text { Bhalla score: } 8.3\end{array}$ \\
\hline $\begin{array}{l}\text { TULEK et al., } 2013 \\
\text { [60] }\end{array}$ & $\begin{array}{l}\text { Stable COPD (BCH or clinical } \\
\text { evidence of } \mathrm{BCH} \text { were excluded) }\end{array}$ & 80 & $68 \pm 8$ & 95 & Radiological COPD phenotypes & $\begin{array}{l}\text { Naidich } \\
\text { Modified Bhalla } \\
\text { (grading) }\end{array}$ & $\begin{array}{c}33.8 \\
\text { Moderate-to-severe } \\
\text { patients: } 40\end{array}$ \\
\hline
\end{tabular}




\begin{tabular}{|c|c|c|c|c|c|c|c|}
\hline Study & $\begin{array}{l}\text { Selection } \\
\text { criteria }\end{array}$ & $\mathbf{n}$ & Age years ${ }^{\#}$ & Male sex $\%$ & Main objective & $\mathrm{BCH}$ criteria & $\mathrm{BCH}$ prevalence \% \\
\hline $\begin{array}{l}\text { Gallego et al., } 2014 \\
\text { [61] }\end{array}$ & $\begin{array}{l}\text { Exacerbate severe COPD with } \\
\text { exacerbator phenotype }\end{array}$ & 118 & $69.5 \pm 8.2$ & $\begin{array}{l}\text { Predominantly } \\
\text { male }\end{array}$ & Prevalence and risk factors for PA & $\begin{array}{l}\text { Naidich (diagnosis) and } \\
\text { Smith (grading) } \\
\text { Score } \leqslant 1 \text { was considered } \\
\text { normal }\end{array}$ & $\begin{array}{c}47 \\
\text { Lower lobes only: } 52 \\
>4 \text { lobes: } 25 \\
\text { BCH score: } 4.2\end{array}$ \\
\hline $\begin{array}{l}\text { GatherAL et al., } 2014 \\
\text { [62] }\end{array}$ & First hospitalised COPD & 406 & $71 \pm 11$ & 56 & $\begin{array}{l}\text { Impact of } \mathrm{BCH} \text { on clinical } \\
\text { outcomes }\end{array}$ & $\begin{array}{l}\text { Naidich } \\
0 \text { labsent)- } 4 \text { severe BCH } \\
\text { points (no reference) }\end{array}$ & $\begin{array}{c}69 \\
\text { Minor: } 40 \\
\text { Mild: } 29 \\
\text { Moderate: } 22 \\
\text { Severe: } 8 \\
\text { Increase with age and } \\
\text { male }\end{array}$ \\
\hline $\begin{array}{l}\text { JaIRAM et al., } 2015 \\
\text { [63] }\end{array}$ & $\begin{array}{l}\text { COPD without previous exacerbations } \\
\text { CT performed due to } \\
\text { non-pulmonary causes) }\end{array}$ & 338 & $71(61-76)^{f}$ & 54 & $\begin{array}{l}\text { Incidental CT findings and risk of } \\
\text { hospitalisation or death due to } \\
\text { COPD exacerbation }\end{array}$ & $\begin{array}{l}\text { Fleischner Society Criteria } \\
\text { (diagnosis) } \\
\text { Lobe-based visual } \\
\text { grading system (0-3 } \\
\text { points per lobe) }\end{array}$ & $\begin{array}{c}32.5 \\
\text { Score=1: } 14 \\
\text { Score }=2: 9 \\
\text { Score }>2: 9\end{array}$ \\
\hline $\begin{array}{l}\text { MAO et al., } 2015 \\
\text { [64] }\end{array}$ & $\begin{array}{l}\text { Stable COPD lonly if previous CT } \\
\text { scan) }\end{array}$ & 896 & $\begin{array}{l}66.2 \pm 9.6 \\
85 \% \text { males }\end{array}$ & & Prognostic value of $\mathrm{BCH}$ & Naidich & 34.7 \\
\hline $\begin{array}{l}\text { DA SILVA et al., } 2016 \\
\text { [65] }\end{array}$ & $\begin{array}{l}\text { Stable COPD } \\
\text { (previous BCH were excluded) }\end{array}$ & 65 & $64.2 \pm 8.5$ & 66 & COPD phenotypes on HRCT & Bhalla system & 33.8 \\
\hline TAN et al., 2016 [45] & Stable COPD (Canadian cohort) & 451 & $62.8-69^{\S}$ & $46-50$ & CT abnormalities & Fleischner Society Criteria & $\begin{array}{c}\text { Mild: } 14.1 \\
\text { Moderate: } 22.2 \\
\text { Severe: } 35.1\end{array}$ \\
\hline Dou et al., 2018 [66] & $\begin{array}{l}\text { Stable COPD (only if CT scan in } \\
\text { previous } 12 \text { months) }\end{array}$ & 1739 & $68.5 \pm 9.7$ & 79.8 & $\begin{array}{l}\text { Relationship between } \\
\text { bronchiectasis and emphysema }\end{array}$ & Bhalla system & 8.1 \\
\hline
\end{tabular}


TABLE 2 Over-diagnosis and under-diagnosis of radiological bronchial dilatation in COPD patients

\section{Over-diagnosis of bronchial dilatation}

Interstitial lung diseases or emphysema

Healthy elderly [45]

Radiological images mimicking bronchiectasis (cystic diseases)

$[75,76]$

False bronchiectasis due to hypoxic vasoconstriction $[43,44]$

Non-tangential CT slides $[75,76]$

\section{Under-diagnosis of bronchial dilatation}

Presence of vascular hypertension increasing vessel size

CT without high-resolution algorithms from apex to pulmonary bases $[75,76]$

COPD: chronic obstructive pulmonary disease; CT: computed tomography.

bronchiectasis, as reflected in severity and prognostic scores such as the Bronchiectasis Severity Index [67] and FACED/E-FACED [68, 69]. A different situation would be the development of bronchiectasis in a smoker with COPD, which would be considered an overlap.

Although there is no evidence for a causal relationship between COPD and bronchiectasis, it seems to be biologically plausible because smoking (or other respiratory exposure) can facilitate chronic bronchial infection and the consequent inflammation may sustain the development of bronchiectasis (figure 1b) [70-72]. Very few studies have recruited random populations of people with COPD or bronchiectasis and carefully assessed subjects for the presence of the other condition; thus, it remains unclear whether the presence of both conditions represents a chance association, or whether there is a causal link. The CanCOLD study [45] included healthy adults, smokers with normal lung function and patients with COPD and found a prevalence of bronchiectasis of $19.9 \%$ in both healthy individuals and smokers without COPD. This prevalence increased to 35\% in severe COPD. This study showed a clear association between bronchiectasis and COPD severity, dyspnoea and poor health status, but no significant association with cough and expectoration [37]. Bronchiectasis in COPD has been proposed as a clinical phenotype [13, 14, 73]. A phenotype, in the context of COPD, is defined as a group of features that predict the natural history and/or treatment response [74]. Ideally this would be stable over time. Patients with COPD may have more than one phenotype, which may overlap [74]. Irrespective of how overlap arises, via chance or as a true association, the presence of bronchiectasis in COPD is associated with poor outcomes, including mortality. MARTíneZ-García et al. [59], for example, reported that bronchiectasis in COPD was associated with an increased risk of exacerbations, and was predictive for mortality over 48 months. Meta-analyses [8, 42] of features of overlap versus COPD alone have also demonstrated associations with older age, male sex, more severe airflow obstruction, greater sputum production, isolation of sputum pathogens (including $P$. aeruginosa) and greater systemic inflammation. Bronchiectasis has also been associated with $\alpha_{1}$-antitrypsin deficiency, with the mechanistic link of incompletely opposed neutrophil elastase activity [77]. However, as with "usual COPD", the true prevalence of bronchiectasis in populations with $\alpha_{1}$-antitrypsin deficiency, and whether this is elevated compared to usual COPD, remains controversial [78].

In cohorts with a primary diagnosis of bronchiectasis, the overlap with COPD is associated with a doubling of the risk of mortality, making it the most relevant prognostic comorbidity after malignancy. In

TABLE 3 Limitations of study designs to analyse the prevalence of bronchiectasis in COPD patients

\section{Over-diagnosis of bronchiectasis}

Inclusion of non-consecutive patients

Retrospective studies

Inclusion of COPD patients during an exacerbation period

Evidence of publication bias

Inconsistent definitions of bronchiectasis

Inclusion of isolated small cylindrical bronchiectasis

in only one pulmonary segment

\section{Under-diagnosis of bronchiectasis}

Exclusion of previous bronchiectasis

Not using validated radiological scores to diagnose bronchiectasis

Exclusion of patients with underlying diseases capable of causing bronchiectasis

Inclusion of non-consecutive patients

Performance of CT scan with an objective other than the diagnosis of bronchiectasis (e.g. emphysema quantification) [54]

Evidence of publication bias

Inconsistent definitions of bronchiectasis 
a) NORMAL AIRWAY AND VESSEL DIMENSIONS

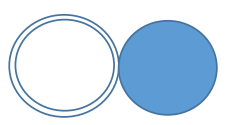

Absence of bronchial dilatation Absence of BWT

Normal vessel diameter Normal B/A ratio

Radiological bronchiectasis: No

VASCULAR HYPERTENSION IN BRONCHIECTASIS

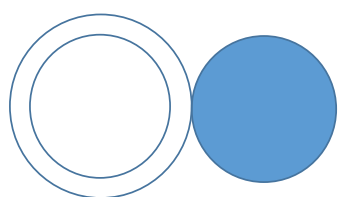

Bronchial dilatation Presence of BWT Increased vessel diameter Normal B/A ratio

Radiological bronchiectasis: Yes

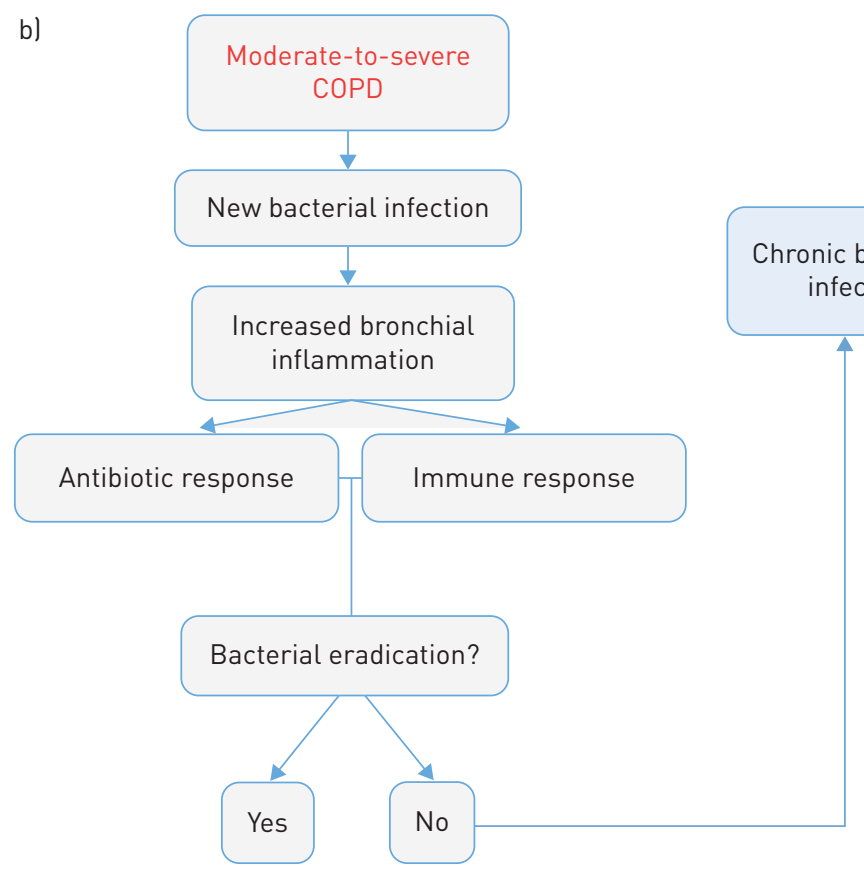

Fall \& Rise hypothesis
AIRWAY DILATATION

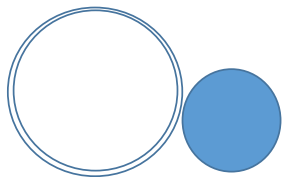

Bronchial dilatation Absence of BWT

Normal vessel diameter Increased $B / A$ ratio

Radiological bronchiectasis: No

VASOCONSTRICTION

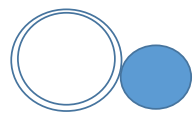

Absence of bronchial dilatation Absence of BWT

Decreased vessel diameter Increased $B / A$ ratio

Radiological bronchiectasis: No
AIRWAY DILATATION AND BRONCHIAL WALL THICKENING

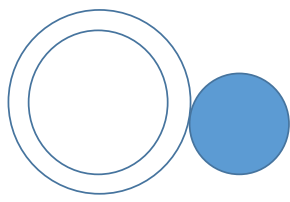

Bronchial dilatation Presence of BWT

Normal vessel diameter Increased $B / A$ ratio

Radiological bronchiectasis: Yes

BRONCHIAL WALL THICKENING WITHOUT BRONCHIECTASIS

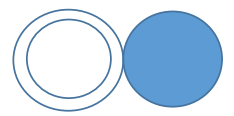

Absence of bronchial dilatation Presence of BWT

Normal vessel diameter Normal B/A ratio

Radiological bronchiectasis: No

Cole's vicious circle

FIGURE 1 a) Broncho-arterial ratio (B/A) in different conditions. BWT: bronchial wall thickening. b) Pathophysiological pathway linking chronic obstructive pulmonary disease (COPD) and bronchiectasis. Reproduced from [14] with permission.

a recent study defining the frequent exacerbator phenotype in bronchiectasis, patients with coexisting COPD had a $43 \%$ increased risk of future exacerbations even after adjustment for prior exacerbation history and other confounders $[10,79]$.

These data support the view that patients identified as having both disorders generally have a worse prognosis. 


\section{Therapeutic consequences}

In a significant number of patients with COPD and bronchiectasis, the main clinical manifestations are those typically associated with bronchiectasis: chronic cough and sputum production, chronic bronchial infection and frequent infective exacerbations [8, 42]. In addition to the use of long-acting bronchodilators, which are the basis of COPD treatment $[47,80]$, we need to provide effective treatment for the bronchiectasis. Therefore, the application of recommendations in guidelines for bronchiectasis is also essential for the management of these overlap patients [48-50]. Macrolides have been investigated in both bronchiectasis and COPD. Recent European guidelines support their chronic use in selected bronchiectasis patients [49]. A meta-analysis by DonATH et al. [81] showed that macrolides can significantly reduce the risk of COPD exacerbations (relative risk reduction 37\%, relative risk $0.63,95 \% \mathrm{CI}$ 0.45-0.87, $\mathrm{p}=0.005$ ) and updated COPD guidelines suggest using macrolides for patients with multiple exacerbations despite long-acting beta agonists/long-acting muscarinic antagonists/inhaled corticosteroids (ICS) [46, 47]. Caution is, however, warranted because there are no studies specifically in COPD-bronchiectasis overlap for either macrolide. There are significant concerns around the use of macrolides, including the induction of cardiovascular effects and antibiotic resistance; this is particularly dangerous in nontuberculous mycobacterial infections (reported in up to $10 \%$ of COPD patients) owing to the increased risk of treatment failure and mortality [82-84].

Inhaled antibiotics are currently not recommended in COPD owing to the considerable risk of side effects (bronchospasm) but there is some evidence suggesting that carefully selected patients, such as those with bronchiectasis and/or with chronic $P$. aeruginosa infection, could benefit from this intervention but clearly more research is needed in this field $[85,86]$.

The risk of acute and chronic bacterial infection implies that special attention must be paid to the use of drugs with possible immunosuppressant activity, such as ICS. There are reports indicating that the use of ICS in COPD may be associated with increased bacterial load in the airways [87] and an increased risk of bacterial pneumonia [88]. A Cochrane review published in 2009 [89] concluded that there is insufficient evidence to recommend the routine use of inhaled steroids in adults with stable state bronchiectasis except for in specific conditions in which the possible benefits in exacerbation reduction outweigh the risks $[48,49,89,90]$.

ICS are primarily effective in eosinophilic inflammation airway diseases such as usual asthma and should therefore not be used in the majority of bronchiectasis patients who have neutrophilic inflammation [91, 92].

\section{Future directions for research}

It is clear that there are significant knowledge gaps in relation to COPD-bronchiectasis overlap [93]. A consensus for criteria defining radiological and clinical bronchiectasis in COPD patients is needed. The true prevalence of bronchiectasis in these patients could be investigated by analysing COPD patients from large international cohorts in order to minimise the risk of selection bias and to have good representation of the COPD population. Moreover, the prognostic value of bronchiectasis in COPD patients should be confirmed by larger prospective studies.

Ideally, a new method to diagnose bronchiectasis independent of the vessel diameter should be validated. To accomplish this, the distribution of normal airway diameters must be measured in the general population and predicted values calculated depending on age, sex, anthropometric variables and airway generation, in a similar way to that in which spirometric parameters are used to diagnose airway obstruction. This measurement would be independent of vessel diameter, and therefore independent of aetiology and respiratory comorbidities. After establishing the radiological diagnosis of bronchial dilatation, bronchiectasis in COPD as an overlap syndrome should only be diagnosed if there is a compatible clinical picture (usually daily productive cough or increase in the volume, viscosity or purulence of the sputum). The presence of bronchial wall thickening as a reflection of bronchial inflammation in an appropriate context could also assist in diagnosis [45].

Other particularly important evidence gaps are the lack of specific biomarkers linking COPD and bronchiectasis, especially those associated with neutrophilic inflammation [94], the possible existence of endotypes related to shared pathophysiological pathways, and genetic and epigenetic alterations leading to changes in the susceptibility to infections and response to treatment [95]. These would answer questions such as why not all patients with COPD present with chronic bronchial infection and/or bronchiectasis.

Better yet would be studies designed to arrest the development and progression of bronchiectasis in COPD, given that firstly this is associated with poor outcomes, and secondly this would allow a cause-effect relationship to be confirmed. Longitudinal studies in COPD are needed that use repeated imaging techniques over time to identify the development of bronchiectasis and associated factors. 
Moreover, studies examining the impact of existing and new interventions in patients with COPD with and without bronchiectasis and chronic bronchial infection are needed. For instance, inhaled corticosteroids currently have little role in the management of bronchiectasis [26-28, 43] but are indicated in some patients with COPD and frequent exacerbations $[46,47]$. There is also more evidence needed for the role of macrolides and other anti-inflammatory molecules such as PDE-4 inhibitors in the overlap syndrome, and the wider role of prophylactic antibiotic treatment, either systemic or by inhalation.

\section{Overlap asthma and bronchiectasis}

Asthma and bronchiectasis are often partners in a complex relationship. Despite a different pathophysiology, these two conditions often show similarities (table 4). In particular, asthma and bronchiectasis have a similar degree of heterogeneity in terms of clinical manifestations and clinical outcomes. Clinical manifestations, such as cough, expectoration, dyspnoea, obstructive pattern and wheezing, may be similar in these two conditions, as demonstrated by the inclusion of bronchiectasis in the differential diagnosis of asthma in all age groups [96]. Moreover, many cases of bronchiectasis due to antibody deficiencies, such as common variable immune deficiency (CVID), show a functional pattern very similar to that of asthma [97]. However, while airway pathology in asthma is characterised by predominantly eosinophilic airway inflammation, epithelial abnormalities (such as thickening of the sub-epithelial layer and an exaggerated release of various cytokines), smooth muscle proliferation and airway thickening, bronchiectasis is mostly characterised by intense neutrophilic inflammation, large to medium bronchial dilatation, epithelial disruption and mucus hyper-secretion [96, 98-103].

A clear causal relationship between the two entities is not well established [26-28, 77], with the potential exception of CVID in which a reversible obstructive pattern with wheezing and the development of bronchiectasis can be a consequence of pneumonia. The detection of bronchiectasis in many patients with severe asthma has generated the hypothesis that bronchial asthma has a causative role in the development of bronchiectasis [104]; however, the detection of bronchiectasis prior to the diagnosis of asthma has also been reported [105]. It is also clear that many patients receive a diagnosis of asthma prior to receiving a diagnosis of bronchiectasis due to initial misdiagnosis. Indeed, in both asthma and bronchiectasis, the imbalance between matrix metalloproteinases (MMPs) and tissue inhibitors of MMPs can lead to the degradation of extracellular matrix, tissue destruction and subsequent remodelling. This imbalance has been clearly described in bronchiectasis but it has also been considered recently in asthma for the development of bronchiectasis [106].

Asthma is a heterogeneous disease: e.g. eosinophilic inflammation is present in most but not all patients, and allergy is present in only $\sim 50 \%$ of patients. In addition, clinical manifestations, natural history and response to treatment can vary widely; however, acute bronchial reversibility and/or hyperresponsiveness can also be observed in other diseases (e.g. COPD). The only constant feature described across all pheno- and endotypes of asthma is the large variability of airway obstruction over time; this is the hallmark of asthma.

Similarly, bronchiectasis is also considered a heterogeneous disease, mainly due to different underlying aetiologies such as respiratory infections (pneumonia, tuberculosis), systemic diseases (rheumatoid arthritis, ulcerative colitis), immunological disorders (antibody deficiency, HIV), COPD and asthma. Accordingly, the clinical manifestation, natural history and response to treatment are also varied $[6,49]$. Airway obstruction is described in $>60 \%$ of bronchiectasis patients, although this obstruction is often not reversible $[19,107]$.

The association of asthma and bronchiectasis has been described in a variable proportion of patients $[4,17,49,104]$. Asthma has been reported in 3-8\% of bronchiectasis patients [108]. Bronchiectasis has

\section{TABLE 4 Main clinical and functional similarities between asthma and bronchiectasis}

Asthma

Chronic respiratory disease with heterogeneous clinical manifestations

Complex pathophysiology

Chronic airway inflammation

Mostly eosinophilic

Ventilatory disorder

Obstructive

Mostly reversible

Exacerbations: marker of disease control

Infectious (viral?)

Non-infectious (allergens, treatment compliance, pollution)

\section{Bronchiectasis}

Chronic respiratory disease with heterogeneous clinical manifestations

Complex pathophysiology

Chronic airway inflammation

Mostly neutrophilic

Ventilatory disorder

Mostly obstructive

Mostly non-reversible

Exacerbations: marker of disease control Infectious (bacterial, viral mixed, fungal) Non-infectious (?) 
been reported in $25-80 \%$ of patients with severe asthma, whereas in mild asthma the prevalence is similar to that reported in the general population $[17,109]$. Nevertheless, airflow obstruction is not required for the diagnosis of bronchiectasis, unlike coexisting asthma or COPD.

Accordingly, the overlap between asthma and bronchiectasis can be viewed in two ways: 1) bronchiectasis in patients with a confirmed diagnosis of asthma; and 2) asthma, or asthma-like features, in patients with bronchiectasis.

\section{Bronchiectasis in asthma}

Bronchiectasis is frequently considered to be a consequence of long-lasting, severe, uncontrolled asthma. In patients with asthma, the reported prevalence of bronchiectasis is extremely variable, depending on patient selection and type/severity of asthma (table 5) [7, 16-18, 104, 110-113]. According to the literature, patients with severe asthma with frequent exacerbations and patients with non-allergic asthma are more likely to have bronchiectasis [7, 113, 114]. Moreover, patients with severe asthma with bronchiectasis are often older and show more severe airway obstruction, and higher rates of chronic expectoration and infection [109]. A potential mechanism for this association is a partial immunodeficiency derived from chronic corticosteroid therapy. Indeed, Lujén et al. [110] found that bronchiectasis was more prevalent in patients with steroid-dependent asthma. Hypogammaglobulinaemia was described in a group of asthma patients in association with an increased risk of bronchiectasis compared to normoglobulinaemia [115]. However, DimAKou et al. [16] recently described bronchiectasis in $67.5 \%$ of patients with severe uncontrolled asthma. The cases were selected after a complete aetiological investigation and aetiologies of bronchiectasis other than asthma were excluded. These patients with severe asthma showed pathogens in sputum (mainly $P$. aeruginosa) in $22.5 \%$ of cases, all concomitant with bronchiectasis [18].

Although patients with severe asthma and bronchiectasis usually do not report tobacco exposure or neutrophilic airway inflammation, they usually have a poorer prognosis in terms of exacerbations and response to asthma treatment, and often require a therapeutic approach typical of bronchiectasis (long-term antibiotics, chest physiotherapy).

In general, it is sensible to suspect bronchiectasis in patients with severe asthma who show a poor response to high-dose ICS and report chronic cough/expectoration, recurrent infectious exacerbations, Aspergillus sensitisation or neutrophilia in the sputum.

Asthma and bronchiectasis can also coexist in ABPA, which is usually characterised by central bronchiectasis, infiltrates, mucus plugging and clinical manifestations of uncontrolled asthma [116, 117]. In the EMBARC database, ABPA has been reported in $0-11 \%$ of all bronchiectasis patients, with a typical decreasing geographic distribution from the north to the south of Europe [4]. This condition responds fairly well to a specific therapy (systemic corticosteroids and antifungal therapy in some cases), with its identification crucial to achieving control of symptoms and Aspergillus sensitisation. In terms of its clinical peculiarities and response to specific treatment, ABPA can be considered a separate clinical entity. However, the persistence of bronchiectasis after ABPA may cause subsequent exacerbations and bacterial colonisation.

\section{Asthma in patients with bronchiectasis}

Although the presence of asthma has been reported in about 3-8\% of all bronchiectasis patients (excluding ABPA) [4, 108], literature on this association is still scarce and the potential influence of asthma on the management and prognosis of bronchiectasis is unclear.

TABLE 5 Prevalence of high-resolution computed tomography-diagnosed bronchiectasis in patients with severe asthma

\begin{tabular}{|c|c|c|c|}
\hline Study & Subjects $\mathbf{n}$ & $\mathrm{BCH}$ prevalence $\%$ & Risk factors associated with $\mathrm{BCH}$ \\
\hline BISACCIONI et al., 2009 [104] & 105 & 24.8 & NR \\
\hline GuPTA et al., 2009 [111] & 467 & 40 & Disease duration, $\mathrm{FEV}_{1} / \mathrm{FVC}<75 \%$ \\
\hline LuJÁn et al., 2013 [110] & 50 SD versus 50 NSD & 40 versus 12 & age and steroid dependence \\
\hline Dıмakou et al., 2017 [18] & 40 & 67.5 & Sputum, antibiotic courses, bacterial colonisation \\
\hline
\end{tabular}

BCH: bronchiectasis; NR: not reported; FEV1: forced expiratory volume in 1 s; FVC: forced vital capacity; SD: steroid-dependent; NSD: non steroid-dependent. 
A recent analysis of the EMBARC database showed that asthma was considered the cause of bronchiectasis in $6.8 \%$ of 7841 patients, but it was also "self-reported" by patients as a comorbidity in $30.5 \%$ of all cases [108]. In this study, patients with self-reported asthma had more frequent exacerbations despite similar levels of disease severity. They had fewer symptoms when clinically stable, suggesting a different clinical phenotype [108].

Two recent papers identified asthma as a relevant risk factor for exacerbations of bronchiectasis [15, 118], despite a lower rate of $P$. aeruginosa infection compared to bronchiectasis patients without asthma [15].

"Asthma-like symptoms" (e.g. chest tightness, wheezing, variable resting dyspnoea) may be reported by patients with bronchiectasis, not only during exacerbations but also in stable disease. These patients do not report a history of childhood asthma, although some of them had been erroneously categorised as "asthmatics". The prevalence of asthma-like symptoms in bronchiectasis has not been evaluated in the literature, and strongly depends on the criteria used to describe asthma (e.g. symptoms alone, acute reversibility of airway obstruction, bronchial hyperresponsiveness, asthma biomarkers like exhaled nitric oxide (NO) or blood/sputum eosinophils). For instance, CHEN et al. [119] suggested that exhaled NO could be a good biomarker to identify asthma in bronchiectasis patients but further investigation is needed to validate its use. In a large database of $>150$ patients, almost $20 \%$ of them had a sputum eosinophil percentage $\geqslant 3 \%$, suggesting some degree of airway eosinophilic inflammation [23]. There was no correlation between sputum eosinophilia and acute reversibility of airway obstruction or other clinical asthma features, suggesting that this biomarker may not be exclusively related to asthma.

According to these few data, we could argue that patients with bronchiectasis and asthma features may represent a different population from those with a long asthma history and concomitant bronchiectasis. It is likely that biomarkers and long-term variability in pulmonary function over time might be important tools to define the "asthma component" in these patients. This characterisation may be relevant for personalising pharmacological treatment.

\section{Future directions for research}

A better characterisation of the population with asthma-bronchiectasis overlap is clearly needed. Defining this overlap condition would help to characterise these patients and their specific therapeutic needs. However, the data available so far are very heterogeneous. A careful screening of updated diagnostic criteria of asthma, including biological, functional and clinical data, in bronchiectasis patients would likely fill the existing gap. Undoubtedly, considering the huge heterogeneity of bronchiectasis patients, a large data set and representation of different geographic areas are needed to adequately describe asthma in the overall bronchiectasis population.

Defining "confirmed" and "potential" asthma-bronchiectasis overlap could help define long-term prognosis and related risk factors. In 1997, KeIsTinen et al. [120] described the prognosis of bronchiectasis as intermediate between COPD and asthma; more recently, it has been shown that COPD-bronchiectasis overlap could have a worse prognosis than for COPD or bronchiectasis alone $[8,9,11]$. Unfortunately, there is no information regarding the prognosis of patients with asthma-bronchiectasis overlap.

No specific therapies have yet been defined for this potential subset of the population. In particular, the following need to be defined: 1) optimal therapy of the airway disease, including bronchodilators, ICS and/or biologic drugs; and 2) appropriate therapy of airway infection, including acute and chronic infections, indications for systemic and inhaled antibiotics, and antiviral drugs.

Moreover, the risks related to chronic therapies have not been investigated. In particular, long-term inhaled steroids could potentially increase the risk of fungal and mycobacterial infections; similarly, effects of long-term antibiotics (e.g. macrolides) on the lung microbiome and immune/inflammatory response should also be investigated.

Finally, further investigation of exacerbations (aetiology, clinical presentation, treatment, inflammatory pattern) in asthma-bronchiectasis patients could contribute to improving their management if a different pheno- or endotype is finally identified.

\section{Upper airway involvement in bronchiectasis}

The respiratory tract is a continuum of ciliated epithelium from the upper to the lower airways. Therefore, it is not surprising that several disease processes, such as CF, PCD and asthma, involve both upper and lower airways. CRS is an inflammatory condition of the nose and paranasal sinuses, defined as a combination of clinical symptoms (nasal congestion or discharge, facial pain, loss of smell) present for at least 12 weeks together with a finding of inflamed mucosa by endoscopy, or a CT scan showing mucosal changes within the osteomeatal complex and/or sinuses (table 6) [121]. CRS is frequent in patients with 


\title{
TABLE 6 Diagnostic criteria for chronic rhinosinusitis
}

\author{
Inflammation of the nose and the paranasal sinuses with two or more symptoms for $>12$ weeks: \\ Nasal blockage \\ Obstruction \\ Congestion \\ Nasal discharge \\ Facial pain/pressure \\ Reduction in olfaction \\ With at least one of the following findings on endoscopy or CT: \\ Nasal polyps \\ Mucopurulent discharge \\ Oedema/mucosal obstruction \\ Mucosal changes
}

CT: computed tomography. Adapted from [121]

asthma and allergy [121-124], and the combination of CRS and bronchiectasis is nearly universal in CF [125] and PCD [21, 126]. In these entities, a common mechanism, e.g. allergic inflammation or a genetic defect, affects both upper and lower airway epithelial function. In bronchiectasis other than CF and PCD, the frequent involvement of the upper airways is also well established [21, 126-128]. The prevalence of CRS among patients with bronchiectasis varies from 34\% to 75\% in European patients with bronchiectasis $[20,121,127-130]$, and is much more common than the $10 \%$ prevalence of CRS in the general population [131]. This association suggests that either a common predisposition or a cause and effect relationship is shared by CRS and bronchiectasis.

The mechanisms of upper airway involvement in bronchiectasis other than CF and PCD have not been well established. CRS is more prevalent in idiopathic than in postinfectious bronchiectasis [132, 133], leading to the assumption that a common mechanism affecting the upper and lower airways causes idiopathic bronchiectasis, whereas localised inflammation of the lung causes postinfectious bronchiectasis with less upper airway involvement. An allergic tendency causing CRS and inflammation of the lower airways has also been suggested [122]. We have found that peripheral blood eosinophils and $\operatorname{IgE}$ are elevated in patients with CRS-bronchiectasis compared to in patients with bronchiectasis without CRS, with a higher prevalence of concomitant asthma among patients with CRS-bronchiectasis (14\% versus $6 \%$ ) [133]. This finding needs exploration, given the usual neutrophilic, rather than eosinophilic, airway inflammation in bronchiectasis [134].

Patients with CRS-bronchiectasis are consistently reported to have significantly more exacerbations than bronchiectasis patients without upper airway involvement $[21,127,133,135]$, with a worse quality of life [136]. Comparisons of lung function between patients with bronchiectasis with and without upper airway involvement have shown contradictory findings [21, 127, 135], with some studies showing worse lung function in patients with CRS involvement $[127,128]$ and others demonstrating the opposite effect [133]. RAMAKRISHNAN et al. [127] compared bacteria present in the upper and lower airways of patients with CRS and bronchiectasis. The prevalence of $P$. aeruginosa colonisation in the lungs and sinuses was 30-35\%, and there was $75-93 \%$ agreement between cultures from sinuses and lungs. Concordance between sinus and lung infection has also been found in CF and PCD [137-139], with P. aeruginosa sinus infection preceding lung infection [138]. It is very plausible given these results that in cases with CRSbronchiectasis, the sinuses act as a reservoir for bacteria that subsequently infect the bronchi. While the mechanisms for the increased exacerbations are not known, it is possible that some of these exacerbations are driven by rhinosinusitis with post-nasal drip causing increased cough.

Treatment of CRS consists of medical and surgical modalities [121]. Applying topical corticosteroids is beneficial in reducing symptoms of nasal secretion and obstruction, and in reducing the size of nasal polyps. Efficacy has been demonstrated for saline irrigation, and irrigation with anti-pseudomonal antibiotics in colonised patients with CF and PCD has also been used as an adjunct to sinus surgery $[139,140]$. In CF, nasal irrigation with recombinant human DNAse has resulted in improvements in nasal symptom score and lung function [141-143]. Recently, sinonasal surgery has been shown to improve bronchiectasis symptoms and decrease the frequency of exacerbations [144]. Long-term treatment with macrolide antibiotics has also been found to reduce symptoms and polyp size $[145,146]$ but another study of long-term azithromycin in CRS did not show such a benefit [147]. According to our own personal experience, inhalation of hypertonic saline through a face mask in patients with CRS-bronchiectasis is beneficial in improving nasal symptoms and mucosal congestion. Sinus surgery, with removal of polyps 
and restoration of the passage of retained secretions, is beneficial in patients with refractory disease [121]. It is important, however, to maintain conservative treatment after surgery in order to prevent the relapse of nasal congestion and retained secretions.

\section{Future directions for research}

Although the association of CRS with bronchiectasis is clear, many questions remain as to the pathogenesis and optimal treatment of the various forms of CRS-bronchiectasis. The pathogenesis of the association with CRS in many patients with idiopathic and postinfectious bronchiectasis is unclear: is CRS developing into bronchiectasis, is bronchiectasis causing CRS, or is a common mechanism predisposing to both? A possible means of exploring this association may be the long-term follow-up of patients with isolated conditions (CRS alone and bronchiectasis alone) to observe the development of the associated condition.

The inflammatory cells present in bronchiectasis airways are dominantly neutrophils, whereas CRS is mostly mediated by an allergic, eosinophilic inflammation. An important area for research is the nature of the inflammatory process in the airways of bronchiectasis patients with CRS, and whether CRS-bronchiectasis represents a distinct endotype, in which airway inflammation may be eosinophilic rather than neutrophilic. This question may have important implications regarding treatment with anti-inflammatory medications, such as ICS. While treatment with ICS has not been established in bronchiectasis [148], individual small studies have found beneficial effects [149-155]. The phenotype of CRS-bronchiectasis may be a distinct subgroup in which the effect of ICS may be beneficial. Large-scale studies addressing this possibility are needed. These studies should also address the phenotypic variation of CRS-bronchiectasis, because patients with PCD and patients with non-PCD-bronchiectasis may display different mechanisms for airway damage, and therefore responses to individual therapies may be quite different.

\section{Conclusions}

Despite great scientific advances in bronchiectasis in recent years, major knowledge gaps still exist on the different clinical aspects that need to be addressed.

The association of bronchiectasis with COPD and asthma has been described in recent years but these clinical overlaps need to be investigated in order to unravel the specific pathophysiology of these conditions. More importantly, both conditions of bronchiectasis overlap with COPD and asthma need a specific definition based on radiological, clinical, functional and biological features. In particular, the presence of chronic bronchial obstruction in non-smoking bronchiectasis patients needs to be better defined from a clinical and biological perspective, given that a specific treatment could therefore be indicated, e.g. ICS in patients with eosinophilic airway inflammation. It is likely that specific therapeutic and follow-up interventions are needed to ensure optimal management of these overlap conditions.

The pathogenetic mechanisms underlying the association of bronchiectasis and upper airway diseases are understood only in the presence of PCD. However, the majority of patients presenting with CRS and bronchiectasis do not seem to have ciliary dysfunction and there is a considerable knowledge gap in this subgroup in terms of risk factors, prognosis and therapy.

All these clinical overlap conditions (COPD, asthma and CRS in association with bronchiectasis) seem to have different prognoses but unfortunately there is still scarce information available. Moreover, it is unknown whether these different clinical entities share any common pathways in terms of airway inflammation and lung injury or to what extent they can be considered different airway diseases. In particular, it is crucial in bronchiectasis to identify overlap-specific risk factors contributing to increased susceptibility to infection (both acute and chronic). Only large databases and longitudinal studies can answer these crucial questions and identify modifiable prognostic factors. Specific biomarkers, more appropriate imaging or functional techniques could support the follow-up of disease progression and help define the personalised management of these overlap conditions.

Finally, we desperately need to define specific therapeutic tools for each overlap disease, or clinical phenotype, according to the underlying inflammatory patterns, risk factors and expected outcomes. As suggested in the past for other chronic respiratory diseases, it is possible that all these different conditions share biological mechanisms that lead to the development of bronchiectasis, but clear differences can be described in terms of the clinical, functional, radiological, microbiological and biological aspects. These differences determine distinct phenotypes, or overlap syndromes, that require targeted interventions $[156,157]$. As such, the concept of precision medicine would perfectly fit this field. A precise intervention on treatable traits could lead to optimal management of each condition and improve short- and long-term outcomes [157]. 
In conclusion, we believe that only personalised medicine can consistently modify the prognosis of bronchiectasis patients and prevent further disease progression through specific interventions directed at the treatable traits of each clinical phenotype or overlap.

Conflict of interest: E. Polverino reports personal fees from Bayer, Grifols, Insmed and Zambon, outside the submitted work. K. Dimakou has nothing to disclose. J. Hurst has nothing to disclose. M.A. Martinez-Garcia reports personal fees from Bayer, Grifols, Zambon, Teva, AstraZeneca, GSK and Novartis, outside the submitted work. M. Miravitlles has nothing to disclose. P. Paggiaro reports grants and personal fees from AstraZeneca, grants and personal fees from Chiesi, personal fees and non-financial support from GSK, personal fees from Guidotti, personal fees and non-financial support from Menarini, personal fees from Mundipharma, personal fees and non-financial support from Novartis, and grants and personal fees from Sanofi, outside the submitted work. M. Shteinberg reports having received research grants from Novartis and Trudell pharma; travel grants from Actelion, Boehringer Ingelheim, GSK and Rafa; speaker's fees from Boehringer Ingelheim, GSK, AstraZeneca, Teva and Novartis; and is a member of the EMBARC collaboration. S. Aliberti reports grants and personal fees from Bayer Healthcare, grants and personal fees from Aradigm Corporation, grants and personal fees from Grifols, personal fees from AstraZeneca, personal fees from Basilea, personal fees from Zambon, personal fees from Novartis, personal fees from Raptor, grants and personal fees from Chiesi, personal fees from Actavis UK Ltd, personal fees from Horizon, and grants and personal fees from INSMED, outside the submitted work. J.D. Chalmers reports grants and personal fees from Bayer, grants and personal fees from Grifols, grants and personal fees from Insmed, personal fees from Zambon, grants and personal fees from Boehringer Ingelheim, grants and personal fees from GSK, grants from AstraZeneca, and grants and personal fees from Pfizer, outside the submitted work.

\section{References}

1 King PT, Holdsworth SR, Freezer NJ, et al. Characterisation of the onset and presenting clinical features of adult bronchiectasis. Respir Med 2006; 100: 2183-2189.

2 Naidich DP, McCauley DI, Khouri NF, et al. Computed tomography of bronchiectasis. J Comput Assist Tomogr 1982; 6: 437-444.

3 Webb WR, Müller NL, Neidich DP. Airways diseases. In: Webb WR, Müller NL, Neidich DP, editors. High-Resolution CT of the Lung. 3rd Edn. Philadelphia, Lippincott, Williams and Wilkins, 1991; pp. 467-546.

4 Lonni S, Chalmers JD, Goeminne PC, et al. Etiology of non-cystic fibrosis bronchiectasis in adults and its correlation to disease severity. Ann Am Thorac Soc 2015; 12: 1764-1770.

5 Aliberti S, Lonni S, Dore S, et al. Clinical phenotypes in adult patients with bronchiectasis. Eur Respir J 2016; 47: 1113-1122.

6 Saleh AD, Chalmers JD, De Soyza A, et al. The heterogeneity of systemic inflammation in bronchiectasis. Respir Med 2017; 127: 33-39.

7 Oguzulgen IK, Kervan F, Ozis T, et al. The impact of bronchiectasis in clinical presentation of asthma. South Med J 2007; 100: 468-471.

8 Du Q, Jin J, Liu X, et al. Bronchiectasis as a comorbidity of chronic obstructive pulmonary disease: a systematic review and meta-analysis. PLoS One 2016; 11: e0150532.

9 Goeminne PC, Scheers H, Decraene A, et al. Risk factors for morbidity and death in non-cystic fibrosis bronchiectasis: a retrospective cross-sectional analysis of CT diagnosed bronchiectatic patients. Respir Res 2012; 13: 21 .

10 McDonnell MJ, Aliberti S, Goeminne PC, et al. Comorbidities and the risk of mortality in patients with bronchiectasis: an international multicentre cohort study. Lancet Respir Med 2016; 4: 969-979.

11 De Soyza A, McDonnell MJ, Goeminne PC, et al. Bronchiectasis rheumatoid overlap syndrome (BROS) is an independent risk factor for mortality in patients with bronchiectasis: a multicentre cohort study. Chest 2017; 151: $1247-1254$.

12 Moss R. Fungi in cystic fibrosis and non-cystic fibrosis bronchiectasis. Semin Respir Crit Care Med 2015; 36: 207-216.

13 Martinez-Garcia MA, Miravitlles M. Bronchiectasis in COPD patients: more than a comorbidity? Int J COPD 2017; 12: 1401-1411.

14 Martínez-García MA, Máiz Carro L, De la Rosa Carillo D. The overlap with bronchiectasis. In: Anzueto A, Heijdra Y, Hurst JR, eds. Controversies in COPD (ERS Monograph). Sheffield, European Respiratory Society, 2015; pp. 96-108.

15 Mao B, Yang JW, Lu HW, et al. Asthma and bronchiectasis exacerbation. Eur Respir J 2016; 47: 1680-1686.

16 Dimakou K, Toumbis M, Tsikritsaki, Ket al. Bronchiectasis in severe uncontrolled asthma. Thorax 2015; 70: Suppl. 3, A109.2.

17 Menzies D, Holmes L, McCumesky G, et al. Aspergillus sensitization is associated with airflow limitation and bronchiectasis in severe asthma. Allergy 2011; 66: 679-685.

18 Dimakou K, Gousiou A, Toumbis M, et al. Investigation of bronchiectasis in severe uncontrolled asthma. Clin Respir J 2017; 12: 1212-1218.

19 Chalmers JD, Aliberti S, Polverino E, et al. The EMBARC European Bronchiectasis Registry: protocol for an international observational study. ERJ Open Res 2016; 2: 00081-2015.

20 Guilemany JM, Angrill J, Alobid I, et al. United airways: the impact of chronic rhinosinusitis and nasal polyps in bronchiectasic patient's quality of life. Allergy 2009; 64: 1524-1529.

21 Shapiro AJ, Zariwala MA, Ferkol T, et al. Diagnosis, monitoring, and treatment of primary ciliary dyskinesia: PCD foundation consensus recommendations based on state of the art review. Pediatr Pulmonol 2016; 51: $115-132$.

22 Gaga M, Bentley AM, Humbert M, et al. Increases in CD4+ T lymphocytes, macrophages, neutrophils and interleukin 8 positive cells in the airways of patients with bronchiectasis. Thorax 1998; 53: 685-691.

23 Dente FL, Bilotta M, Bartoli ML, et al. Neutrophilic bronchial inflammation correlates with clinical and functional findings in patients with noncystic fibrosis bronchiectasis. Mediators Inflamm 2015; 2015: 642503. 
Chalmers JD, Hill AT. Mechanisms of immune dysfunction and bacterial persistence in non-cystic fibrosis bronchiectasis. Mol Immunol 2013; 55: 27-34.

Chalmers JD, Moffitt KL, Suarez-Cuartin G, et al. Neutrophil elastase activity is associated with exacerbations and lung function decline in bronchiectasis. Am J Respir Crit Care Med 2017; 195: 1384-1393.

Wenzel SE. Asthma: defining of the persistent adult phenotypes. Lancet 2006; 368: 804-813.

Mandal P, Morice AH, Chalmers JD, et al. Symptoms of airway reflux predict exacerbations and quality of life in bronchiectasis. Respir Med 2013; 107: 1008-1013.

Koh W-J, Lee JH, Kwon YS, et al. Prevalence of gastroesophageal reflux disease in patients with nontuberculous mycobacterial lung disease. Chest 2007; 131: 1825-1830.

Ahn B, Lee DH, Lee CM, et al. Effect of proton pump inhibitors in bronchiectatic patients with gastroesophageal reflux disease. Korean J Gastroenterol 2016; 68: 10-15.

Broers C, Tack J, Pauwels A. Review article: gastro-oesophageal reflux disease in asthma and chronic obstructive pulmonary disease. Aliment Pharmacol Ther 2018; 47: 176-191.

Anzić SA, Turkalj M, Župan A, et al. Eight weeks of omeprazole $20 \mathrm{mg}$ significantly reduces both laryngopharyngeal reflux and comorbid chronic rhinosinusitis signs and symptoms: randomised, double-blind, placebo-controlled trial. Clin Otolaryngol 2018; 43: 496-501.

Whiting $\mathrm{P}, \mathrm{Al} \mathrm{M}$, Burgers $\mathrm{L}$, et al. Ivacaftor for the treatment of patients with cystic fibrosis and the G551D mutation: a systematic review and cost-effectiveness analysis. Health Technol Assess 2014; 18: 1-106.

Deeks ED. Lumacaftor/ivacaftor: a review in cystic fibrosis. Drugs 2016; 76: 1191-1201.

Donaldson SH, Pilewski JM, Griese M, et al. Tezacaftor/ivacaftor in subjects with cystic fibrosis and F508del/ F508del-CFTR or F508del/G551D-CFTR. Am J Respir Crit Care Med 2018; 197: 214-224.

Lucas JS, Barbato A, Collins SA, et al. European Respiratory Society guidelines for the diagnosis of primary ciliary dyskinesia. Eur Respir J 2017; 49: 1601090.

Cosío BG, de Llano LP, Viña AL, et al. Th-2 signature in chronic airway diseases: towards the extinction of asthma-COPD overlap syndrome? Eur Respir J 2017; 49: 1602397.

study. Eur Respir J 2017; 49: 1602008.

Sin DD, Miravitlles M, Mannino DM, et al. What is asthma-COPD overlap syndrome? Towards a consensus definition from a round table discussion. Eur Respir J 2016; 48: 664-673.

Lin H, Jiang S. Combined pulmonary fibrosis and emphysema (CPFE): an entity different from emphysema or pulmonary fibrosis alone. J Thorac Dis 2015; 7: 767-779.

Jacob J, Bartholmai BJ, Rajagopalan S, et al. Functional and prognostic effects when emphysema complicates idiopathic pulmonary fibrosis. Eur Respir J 2017; 50: 1700379.

O'Brien C, Guest PJ, Hill SL, et al. Physiological and radiological characterisation of patients diagnosed with chronic obstructive pulmonary disease in primary care. Thorax 2000; 55: 635-642.

Ni Y, Shi G, Yu Y, et al. Clinical characteristics of patients with chronic obstructive pulmonary disease with comorbid bronchiectasis: a systemic review and meta-analysis. Int J Chron Obstruct Pulmon Dis 2015; 1465.

Diaz AA, Young TP, Maselli DJ, et al. Quantitative CT measures of bronchiectasis in smokers. Chest 2017; 151: 1255-1262.

Diaz AA, Young TP, Maselli DJ, et al. Bronchoarterial ratio in never-smokers adults: implications for bronchia dilation definition. Respirology 2017; 22: 108-113.

Tan WC, Hague CJ, Leipsic J, et al. Findings on thoracic computed tomography scans and respiratory outcomes in persons with and without chronic obstructive pulmonary disease: a population-based cohort study. PLoS One 2016; 11: e0166745.

Vogelmeier CF, Criner GJ, Martinez FJ, et al. Global Strategy for the Diagnosis, Management, and Prevention of Chronic Obstructive Lung Disease 2017 Report: GOLD executive summary. Eur Respir J 2017; 49: 1700214.

Miravitlles M, Soler-Cataluña JJ, Calle M, et al. Spanish Guidelines for Management of Chronic Obstructive Pulmonary Disease (GesEPOC) 2017. Pharmacological treatment of stable phase. Arch Bronconeumol 2017; 53: 324-335.

Pasteur MC, Bilton D, Hill AT, et al. British Thoracic Society guideline for non-CF bronchiectasis. Thorax 2010; 65: $1-58$.

Polverino E, Goeminne PC, McDonnell MJ, et al. European Respiratory Society guidelines for the management of adult bronchiectasis. Eur Respir J 2017; 50: 1700629.

Martínez-García MÁ, Máiz L, Olveira C, et al. Spanish guidelines on the evaluation and diagnosis of bronchiectasis in adults. Arch Bronconeumol 2018; 54: 79-87.

Patel IS, Vlahos I, Wilkinson TMA, et al. Bronchiectasis, exacerbation indices, and inflammation in chronic obstructive pulmonary disease. Am J Respir Crit Care Med 2004; 170: 400-407.

Roche N, Kouassi B, Rabbat A, et al. Yield of sputum microbiological examination in patients hospitalized for exacerbations of chronic obstructive pulmonary disease with purulent sputum. Respiration 2007; 74: 19.

Garcia-Vidal C, Almagro P, Romaní V, et al. Pseudomonas aeruginosa in patients hospitalised for COPD exacerbation: a prospective study. Eur Respir J 2009; 34: 1072-1078.

Agusti A, Calverley PMA, Celli B, et al. Characterisation of COPD heterogeneity in the ECLIPSE cohort. Respir Res 2010; 11: 122.

Bafadhel M, Umar I, Gupta S, et al. The role of CT scanning in multidimensional phenotyping of COPD. Chest 2011; 140: 634-642.

Martínez-García MÁ, Soler-Cataluña JJ, Donat-Sanz Y, et al. Factors associated with bronchiectasis in chronic obstructive pulmonary disease patients. Chest 2011; 140: 1130-1137.

Arram EO, Elrakhawy MM. Bronchiectasis in COPD patients. Egypt J Chest Dis Tuberc 2012; 61: 307-312.

Steward JI, Maselli DJ Anzueto A. Clinical impact of CT radiological feature of bronchiectasis in the COPDGene cohort. Am J Respir Crit Care Med 2012; 185: A3656.

Martínez-García M-A, de la Rosa Carrillo D, Soler-Cataluña J-J, et al. Prognostic value of bronchiectasis in patients with moderate-to-severe chronic obstructive pulmonary disease. Am J Respir Crit Care Med 2013; 187: $823-831$. 
Tulek B, Kivrak AS, Ozbek S, et al. Phenotyping of chronic obstructive pulmonary disease using the modified Bhalla scoring system for high-resolution computed tomography. Can Respir J 2013; 20: 91-96.

Gallego M, Pomares X, Espasa M, et al. Pseudomonas aeruginosa isolates in severe chronic obstructive pulmonary disease: characterization and risk factors. BMC Pulm Med 2014; 14: 103.

Gatheral T, Kumar N, Sansom B, et al. COPD-related bronchiectasis; independent impact on disease course and outcomes. COPD 2014; 11: 605-614.

Jairam PM, van der Graaf Y, Lammers J-WJ, et al. Incidental findings on chest CT imaging are associated with increased COPD exacerbations and mortality. Thorax 2015; 70: 725-731.

Mao B, Lu H-W, Li M-H, et al. The existence of bronchiectasis predicts worse prognosis in patients with COPD. Sci Rep 2015; 5: 10961.

da Silva SMD, Paschoal IA, De Capitani EM, et al. COPD phenotypes on computed tomography and its correlation with selected lung function variables in severe patients. Int J Chron Obstruct Pulmon Dis 2016; 11: 503-513.

Dou S, Zheng C, Ji X, et al. Co-existence of COPD and bronchiectasis: a risk factor for a high ratio of main pulmonary artery to aorta diameter (PA:A) from computed tomography in COPD patients. Int J Chron Obstruct Pulmon Dis 2018; 13: 675-681.

Chalmers JD, Goeminne P, Aliberti S, et al. The Bronchiectasis Severity Index. An international derivation and validation study. Am J Respir Crit Care Med 2014; 189: 576-585.

Martínez-García MA, De Gracia J, Relat MV, et al. Multidimensional approach to non-cystic fibrosis bronchiectasis: The FACED score. Eur Respir J 2014; 43: 1357-1367.

Martinez-Garcia MA, Athanazio RA, Girón R, et al. Predicting high risk of exacerbations in bronchiectasis: the E-FACED score. Int J Chron Obs Pulmon Dis 2017; 18: 275:284.

Wilkinson TM, Patel IS, Wilks M, et al. Airway bacterial load and FEV1 decline in patients with chronic obstructive pulmonary disease. Am J Respir Crit Care Med 2003; 167: 1090-1095.

Matkovic Z, Miravitlles M. Chronic bronchial infection in COPD. Is there an infective phenotype? Respir Med 2013; 107: 10-22.

Garcha DS, Thurston SJ, Patel ARC, et al. Changes in prevalence and load of airway bacteria using quantitative PCR in stable and exacerbated COPD. Thorax 2012; 67: 1075-1080.

Hurst JR, Elborn JS, De Soyza A, et al. COPD-bronchiectasis overlap syndrome. Eur Respir J 2015; 45: 310-313.

Han MK, Agusti A, Calverley PM, et al. Chronic obstructive pulmonary disease phenotypes: the future of COPD. Am J Respir Crit Care Med 2010; 182: 598-604.

McGuinness G, Naidich DP. CT of airways disease and bronchiectasis. Radiol Clin North Am 2002; 40: 1-19. Bonavita J, Naidich DP. Imaging of bronchiectasis. Clin Chest Med 2012; 33: 233-248.

Parr DG, Guest PG, Reynolds JH, et al. Prevalence and impact of bronchiectasis in alpha1-antitrypsin deficiency. Am J Respir Crit Care Med 2007; 176: 1215-1221.

Miravitlles M, Dirksen A, Ferrarotti I, et al. European Respiratory Society statement: diagnosis and treatment of pulmonary disease in $\alpha_{1}$-antitrypsin deficiency. Eur Respir J 2017; 50: 1700610.

Chalmers JD, Aliberti S, Filonenko A, et al. Characterisation of the "frequent exacerbator phenotype" in bronchiectasis. Am J Respir Crit Care Med 2018; 197: 1410-1420.

Wedzicha JA, Calverley PMA, Albert RK, et al. Prevention of COPD exacerbations: a European Respiratory Society/American Thoracic Society guideline. Eur Respir J 2017; 50: 1602265.

Donath E, Chaudhry A, Hernandez-Aya LF, et al. A meta-analysis on the prophylactic use of macrolide antibiotics for the prevention of disease exacerbations in patients with chronic obstructive pulmonary disease. Respir Med 2013; 107: 1385-1392.

Mustafa M-H, Khandekar S, Tunney MM, et al. Acquired resistance to macrolides in Pseudomonas aeruginosa from cystic fibrosis patients. Eur Respir J 2017; 49: 1601847.

Char A, Hopkinson NS, Hansell DM, et al. Evidence of mycobacterial disease in COPD patients with lung volume reduction surgery; the importance of histological assessment of specimens: a cohort study. BMC Pulm Med 2014; 14: 124.

Larsson L-O, Polverino E, Hoefsloot W, et al. Pulmonary disease by non-tuberculous mycobacteria - clinical management, unmet needs and future perspectives. Expert Rev Respir Med 2017; 11: 977-989.

Wilson R, Sethi S, Anzueto A, et al. Antibiotics for treatment and prevention of exacerbations of chronic obstructive pulmonary disease. J Infect 2013; 67: 497-515.

Dal Negro R, Micheletto C, Tognella S, et al. Tobramycin nebulizer solution in severe COPD patients colonized with Pseudomonas aeruginosa: effects on bronchial inflammation. Adv Ther 2008; 25: 1019-1030.

Contoli M, Pauletti A, Rossi MR, et al. Long-term effects of inhaled corticosteroids on sputum bacterial and viral loads in COPD. Eur Respir J 2017; 50: 1700451.

Singh S, Loke YK. Risk of pneumonia associated with long-term use of inhaled corticosteroids in chronic obstructive pulmonary disease: a critical review and update. Curr Opin Pulm Med 2010; 16: 118-122.

Kapur N, Bell S, Kolbe J, et al. Inhaled steroids for bronchiectasis. Cochrane Database Syst Rev 2009; 1: CD000996.

Martínez-García MÁ, Máiz L, Olveira C, et al. Spanish guidelines on treatment of bronchiectasis in adults. Arch Bronconeumol 2018; 54: 88-98.

Gibson PG. Inflammatory phenotypes in adult asthma: clinical applications. Clin Respir J 2009; 3: 198-206.

Pavord ID, Agusti A. Blood eosinophil count: a biomarker of an important treatable trait in patients with airway disease. Eur Respir J 2016; 47: 1299-1303.

Aliberti S, Masefield S, Polverino E, et al. Research priorities in bronchiectasis: a consensus statement from the EMBARC Clinical Research Collaboration. Eur Respir J 2016; 48: 632-647. and lung function decline in bronchiectasis. Am J Respir Crit Care Med 2017; 195: 1384-1393. emphysema and airway phenotypes in severe COPD. Eur Respir J 2011; 37: 39-43.

Global Initiative for Asthma. Global Strategy For Asthma Management And Prevention (GINA Update 2017) http://ginasthma.org/2018-gina-report-global-strategy-for-asthma-management-and-prevention/ 
Touw CML, van de Ven AA, de Jong PA, et al. Detection of pulmonary complications in common variable immunodeficiency. Pediatr Allergy Immunol 2010; 21: 793-805.

98 Saglani S, Lloyd CM. Novel concepts in airway inflammation and remodelling in asthma. Eur Respir J 2015; 46: 1796-1804.

99 Milliron B, Henry TS, Veeraraghavan S, et al. Bronchiectasis: mechanisms and imaging clues of associated common and uncommon diseases. Radiographics 2015; 35: 1011-1030.

100 Moulton BC, Barker AF. Pathogenesis of bronchiectasis. Clin Chest Med 2012; 33: 211-217.

101 King P. Pathogenesis of bronchiectasis. Paediatr Respir Rev 2011; 12: 104-110.

102 Bourdin A, Neveu D, Vachier I, et al. Specificity of basement membrane thickening in severe asthma. J Allergy Clin Immunol 2007; 119: 1367-1374.

103 Haworth O, Levy BD. Endogenous lipid mediators in the resolution of airway inflammation. Eur Respir J 2007; 30: 980-992.

104 Bisaccioni C, Aun MV, Cajuela E, et al. Comorbidities in severe asthma: frequency of rhinitis, nasal polyposis, gastroesophageal reflux disease, vocal cord dysfunction and bronchiectasis. Clinics 2009; 64: 769-773.

105 Jones RCM, Price D, Ryan D, et al. Respiratory Effectiveness Group. Opportunities to diagnose chronic obstructive pulmonary disease in routine care in the UK: a retrospective study of a clinical cohort. Lancet Respir Med 2014; 2: 267-276.

106 Polverino E, Rosales-Mayor E, Dale GE, et al. The role of neutrophil elastase inhibitors in lung diseases. Chest 2017; 152: 249-262.

107 Olveira C, Padilla A, Martínez-García M-Á, et al. Etiology of bronchiectasis in a cohort of 2047 patients. An analysis of the Spanish historical bronchiectasis registry. Arch Bronconeumol 2017; 53: 366-374.

108 Polverino E, Paggiaro P, Aliberti S, et al. Self-reported asthma as a co-morbidity of bronchiectasis in the EMBARC registry. Abstract Book - Second World Bronchiectasis Conference Milan, 6-8 July 2017. www.worldbronchiectasis-conference.org/wp-content/uploads/2017/07/AbstractBook_WEB.pdf. Date last accessed: July 22, 2018.

109 Porsbjerg C, Menzies-Gow A. Co-morbidities in severe asthma: clinical impact and management. Respirology 2017; 22: 651-661.

110 Luján M, Gallardo X, Amengual MJ, et al. Prevalence of bronchiectasis in asthma according to oral steroid requirement: influence of immunoglobulin levels. Biomed Res Int 2013; 2013: 1-7.

111 Gupta S, Siddiqui S, Haldar P, et al. Qualitative analysis of high-resolution CT scans in severe asthma. Chest 2009; 136: 1521-1528.

112 Gupta S, Siddiqui S, Haldar P, et al. Quantitative analysis of high-resolution computed tomography scans in severe asthma subphenotypes. Thorax 2010; 65: 775-781.

113 Paganin F, Séneterre E, Chanez P, et al. Computed tomography of the lungs in asthma: influence of disease severity and etiology. Am J Respir Crit Care Med 1996; 153: 110-114.

114 Machado D, Pereira C, Teixeira L, et al. Thoracic high resolution computed tomography (HRCT) in asthma. Eur Ann Allergy Clin Immunol 2009; 41: 139-145.

115 Dupin C, Marchand-Adam S, Favelle O, et al. Asthma and hypogammaglobulinemia: an asthma phenotype with low type 2 inflammation. J Clin Immunol 2016; 36: 810-817.

116 Greenberger PA, Bush RK, Demain JG, et al. Allergic bronchopulmonary aspergillosis. J Allergy Clin Immunol Pract 2014; 2: 703-708.

117 Shah A, Panjabi C. Allergic bronchopulmonary aspergillosis: a perplexing clinical entity. Allergy Asthma Immunol Res 2016; 8: 282-297.

118 Venning V, Bartlett J, Jayaram L. Patients hospitalized with an infective exacerbation of bronchiectasis unrelated to cystic fibrosis: clinical, physiological and sputum characteristics. Respirology 2017; 22: 922-927.

119 Chen FJ, Liao H, Huang XY, et al. Importance of fractional exhaled nitric oxide in diagnosis of bronchiectasis accompanied with bronchial asthma. J Thorac Dis. 2016; 8: 992-999.

120 Keistinen T, Säynäjäkangas O, Tuuponen T, et al. Bronchiectasis: an orphan disease with a poorly-understood prognosis. Eur Respir J 1997; 10: 2784-2787.

121 Fokkens WJ, Lund VJ, Mullol J, et al. EPOS 2012: European position paper on rhinosinusitis and nasal polyps 2012. A summary for otorhinolaryngologists. Rhinology 2012; 50: 1-12.

122 Bourdin A, Gras D, Vachier I, et al. Upper airway 1: allergic rhinitis and asthma: united disease through epithelial cells. Thorax 2009; 64: 999-1004.

123 Licari A, Caimmi S, Bosa L, et al. Rhinosinusitis and asthma: a very long engagement. Int J Immunopathol Pharmacol 27: 499-508.

124 Jarvis D, Newson R, Lotvall J, et al. Asthma in adults and its association with chronic rhinosinusitis: the GA2LEN survey in Europe. Allergy 2012; 67: 91-98.

125 Gentile VG, Isaacson G. Patterns of sinusitis in cystic fibrosis. Laryngoscope 1996; 106: 1005-1009.

126 Loebinger MR, Bilton D, Wilson R. Upper airway 2: bronchiectasis, cystic fibrosis and sinusitis. Thorax 2009; 64: 1096-1101.

127 Ramakrishnan VR, Ferril GR, Suh JD, et al. Upper and lower airways associations in patients with chronic rhinosinusitis and bronchiectasis. Int Forum Allergy Rhinol 2013; 3: 921-927.

128 Guan W, Gao Y, Li H, et al. Impacts of co-existing chronic rhinosinusitis on disease severity and risks of exacerbations in Chinese adults with bronchiectasis. PLoS One 2015; 10: e0137348.

129 Benninger M, Ferguson B, Hadley J, et al. Adult chronic rhinosinusitis: definitions, diagnosis, epidemiology, and pathophysiology. Otolaryngol Head Neck Surg 2003; 129: Suppl. 3, S1-S32.

130 Shirahata Y. [Correlation between upper airway tract and lower airway tract in the break down of sinobronchiectasis]. Nihon Jibiinkoka Gakkai Kaiho 1990; 93: 1991-1998.

131 Hastan D, Fokkens WJ, Bachert C, et al. Chronic rhinosinusitis in Europe - an underestimated disease. A GA2LEN study. Allergy 2011; 66: 1216-1223.

132 Shoemark A, Ozerovitch L, Wilson R. Aetiology in adult patients with bronchiectasis. Respir Med 2007; 101: 1163-1170.

133 Shteinberg M, Nassrallah N, Jrbashyan J, et al. Upper airway involvement in bronchiectasis is marked by early age of onset and allergic features. ERJ Open Res 2018; 4: 00115-2017. 
Chalmers JD, Smith MP, McHugh BJ, et al. Short- and long-term antibiotic treatment reduces airway and systemic inflammation in non-cystic fibrosis bronchiectasis. Am J Respir Crit Care Med 2012; 186: 657-665.

Guilemany JM, Mariño-Sánchez FS, Angrill J, et al. The importance of smell in patients with bronchiectasis. Respir Med 2011; 105: 44-49.

Guilemany JM, Alobid I, Angrill J, et al. The impact of bronchiectasis associated to sinonasal disease on quality of life. Respir Med 2006; 100: 1997-2003.

Hansen SK, Rau MH, Johansen HK, et al. Evolution and diversification of Pseudomonas aeruginosa in the paranasal sinuses of cystic fibrosis children have implications for chronic lung infection. ISME J 2012; 6: 31-45.

Roby BB, McNamara J, Finkelstein M, et al. Sinus surgery in cystic fibrosis patients: comparison of sinus and lower airway cultures. Int J Pediatr Otorhinolaryngol 2008; 72: 1365-1369.

Alanin MC, Johansen HK, Aanaes K, et al. Simultaneous sinus and lung infections in patients with primary ciliary dyskinesia. Acta Otolaryngol 2015;58-63.

Alanin MC, Aanaes K, Høiby N, et al. Sinus surgery can improve quality of life, lung infections, and lung function in patients with primary ciliary dyskinesia. Int Forum Allergy Rhinol 2017; 7: 240-247.

Mainz J, Mentzel HJ, Schneider G, et al. Sinu-nasal inhalation
placebo-controlled pilot trial. J Cyst Fibros 2008; 7: Suppl. 2, S27.

Mainz JG, Schiller I, Ritschel C, et al. Sinonasal inhalation of dornase alfa in CF: a double-blind placebo-controlled cross-over pilot trial. Auris Nasus Larynx 2011; 38: 220-227.

Mainz JG, Schien C, Schiller I, et al. Sinonasal inhalation of dornase alfa administered by vibrating aerosol to cystic fibrosis patients: a double-blind placebo-controlled cross-over trial. J Cyst Fibros 2014; 13: 461-470.

Wang Y, Yang H-B. Effects of functional endoscopic sinus surgery on the treatment of bronchiectasis combined with chronic rhino-sinusitis. Acta Otolaryngol 2016; 136: 860-863.

Wallwork B, Coman W, Mackay-Sim A, et al. A double-blind, randomized, placebo-controlled trial of macrolide in the treatment of chronic rhinosinusitis. Laryngoscope 2006; 116: 189-193.

Haxel BR, Clemens M, Karaiskaki N, et al. Controlled trial for long-term low-dose erythromycin after sinus surgery for chronic rhinosinusitis. Laryngoscope 2015; 125: 1048-1055.

Videler WJ, Badia L, Harvey RJ, et al. Lack of efficacy of long-term, low-dose azithromycin in chronic rhinosinusitis: a randomized controlled trial. Allergy 2011; 66: 1457-1468.

Goyal V, Chang AB. Combination inhaled corticosteroids and long-acting beta2-agonists for children and adults with bronchiectasis. Cochrane Database Syst Rev 2014; 6: CD010327.

Elborn JS, Johnston B, Allen F, et al. Inhaled steroids in patients with bronchiectasis. Respir Med 1992; 86: $121-124$.

Tsang KW, Ho PL, Lam WK, et al Inhaled fluticasone reduces sputum inflammatory indices in severe bronchiectasis. Am J Respir Crit Care Med 1998; 158: 723-727.

therapy. Int J Tuberc Lung Dis 2004; 8: 1301-1307. patients with steady-state bronchiectasis. Respir Med 2006; 100: 1623-1632.

Martínez-García MÁ, Soler-Cataluña JJ, Catalán-Serra P, et al. Clinical efficacy and safety of budesonide-formoterol in non-cystic fibrosis bronchiectasis. Chest 2012; 141: 461-468.

Hernando R, Drobnic ME, Cruz MJ, et al. Budesonide efficacy and safety in patients with bronchiectasis not due to cystic fibrosis. Int J Clin Pharm 2012; 34: 644-650.

Wei P, Yang J-W, Lu H-W, et al. Combined inhaled corticosteroid and long-acting $\beta 2$-adrenergic agonist therapy for noncystic fibrosis bronchiectasis with airflow limitation: an observational study. Medicine (Baltimore) 2016; 95: e5116.

Wardlaw AJ, Silverman M, Siva R, et al. Multi-dimensional phenotyping: towards a new taxonomy for airway disease. Clin Exp Allergy 2005; 35: 1254-1262.

Agusti A, Bel E, Thomas M, et al. Treatable traits: toward precision medicine of chronic airway diseases. Eur Respir J 2016; 47: 410-419. 